Article

\title{
Anti-Inflammatory and Neuromodulatory Effects Induced by Tanacetum parthenium Water Extract: Results from In Silico, In Vitro and Ex Vivo Studies
}

\author{
Lucia Recinella ${ }^{1}$, Annalisa Chiavaroli ${ }^{1}$, Viviana di Giacomo ${ }^{1}$ (D), Marco Daniel Antolini ${ }^{1}$, \\ Alessandra Acquaviva 1,2, Sheila Leone ${ }^{1}$, Luigi Brunetti ${ }^{1}$, Luigi Menghini ${ }^{1} \mathbb{D}$, Gunes Ak ${ }^{3}$, Gokhan Zengin ${ }^{3, *(D)}$, \\ Simonetta Cristina Di Simone ${ }^{1}$, Claudio Ferrante ${ }^{1, *(\mathbb{D})}$ and Giustino Orlando ${ }^{1}$
}

Citation: Recinella, L.; Chiavaroli, A.; di Giacomo, V.; Antolini, M.D.; Acquaviva, A.; Leone, S.; Brunetti, L.; Menghini, L.; Ak, G.; Zengin, G.; Di Simone, S.C.; et al. Anti-Inflammatory and Neuromodulatory Effects Induced by Tanacetum parthenium Water Extract: Results from In Silico, In Vitro and Ex Vivo Studies. Molecules 2021, 26, 22. https://dx.doi.org/10.3390/molecules 26010022

Academic Editor: Luisa Tesoriere Received: 2 December 2020

Accepted: 21 December 2020

Published: 23 December 2020

Publisher's Note: MDPI stays neutral with regard to jurisdictional claims in published maps and institutional affiliations.

Copyright: (c) 2020 by the authors. Licensee MDPI, Basel, Switzerland. This article is an open access article distributed under the terms and conditions of the Creative Commons Attribution (CC BY) license (https: / / creativecommons.org/ licenses/by/4.0/).
1 Department of Pharmacy, Università degli Studi "Gabriele d'Annunzio", via dei Vestini 31, 66100 Chieti, Italy; lucia.recinella@unich.it (L.R.); annalisa.chiavaroli@unich.it (A.C.); viviana.digiacomo@unich.it (V.d.G.); marcodaniel.antolini@studenti.unich.it (M.D.A.); alessandra.acquaviva@studenti.unich.it (A.A.); sheila.leone@unich.it (S.L.); luigi.brunetti@unich.it (L.B.); luigi.menghini@unich.it (L.M.); disimonesimonetta@gmail.com (S.C.D.S.); giustino.orlando@unich.it (G.O.)

2 Veridia Italia Srl, via Raiale 285, 65100 Pescara, Italy

3 Department of Biology, Science Faculty, Selcuk University, Campus, 42130 Konya, Turkey; akguneselcuk@gmail.com

* Correspondence: gokhanzengin@selcuk.edu.tr (G.Z.); claudio.ferrante@unich.it (C.F.); Tel.: +90-332-223-2781 (G.Z.); +39-0871-355-4753 (C.F.); Fax: +90-332-223-8840 (G.Z.); +39-0871-355-4755 (C.F.)

\begin{abstract}
Tanacetum parthenium (feverfew) has traditionally been employed as a phytotherapeutic remedy in the treatment of migraine. In this study, a commercial T. parthenium water extract was investigated to explore its anti-inflammatory and neuromodulatory effects. Isolated mouse cortexes were exposed to a $\mathrm{K}^{+} 60 \mathrm{mM}$ Krebs-Ringer buffer and treated with T. parthenium water extract. The prostaglandin $\mathrm{E}_{2}\left(\mathrm{PGE}_{2}\right)$ level, brain-derived neurotrophic factor (BDNF), interleukin-10 (IL-10), and IL-1 $\beta$ gene expression were evaluated in the cortex. The effects on dopamine (DA) release and dopamine transporter (DAT) gene expression were assayed in hypothalamic HypoE22 cells. A bioinformatics analysis was conducted to further investigate the mechanism of action. The extract was effective in reducing cortex $\mathrm{PGE}_{2}$ release and IL- $1 \beta$ gene expression. In the same experimental system, IL-10 and BDNF gene expressions increased, and in HypoE22 cells, the extract decreased the extracellular dopamine level and increased the DAT gene expression due to the direct interaction of parthenolide with the DAT. Overall, the present findings highlight the efficacy of T. parthenium water extract in controlling the inflammatory pathways that occur during cortical-spreading depression. Additionally, the inhibition of the hypothalamic DA release observed in this study further supports the role of dopaminergic pathways as key targets for novel pharmacological approaches in the management of migraine attacks.
\end{abstract}

Keywords: Tanacetum parthenium; cortical spreading depression; hypothalamus; interleukins; brainderived neurotrophic factor; dopamine

\section{Introduction}

Migraine is one of the most prevalent neurovascular disorders, the incidence of which ranges from $8 \%$ to $14.7 \%$ of people. The disease begins in childhood, with a tendency to worsen during adulthood (22-55 years of age). Women experience a higher incidence compared to men (3:1) [1]. Serotonin (5-HT) depletion and trigemino-vascular system activation are notoriously involved in migraine pathophysiology [2-6], although the origin site and mechanisms at the basis of migraine are still a matter of debate. In this context, cortical spreading depression (CSD), a supraphysiological and neurotoxic depolarizing stimulus, has been described as a putative link between 5-HT depletion and trigeminal 
nociception [7]. The involvement of the hypothalamus in the complex pathophysiological events underlying migraine attacks has also been suggested [8]. While it also plays a key role in regulating hormone release and energy balance [9], the hypothalamus is anatomically connected with the brain's pain-modulating system and trigeminal nuclei, which regulate nociception [8]. Hypothalamic orexigenic factors, specifically orexins and dopamine (DA), are possibly involved both in CSD and migraine [10-12]. In this context, the use of metoclopramide, a DA receptor antagonist, in controlling the clinical symptoms related to migraine [13] is sensible, although the recommended first-line treatments for mild to moderate forms of migraine are non-steroidal anti-inflammatory drugs and acetaminophen, whereas triptans are recommended in more severe migraine attacks [14]. In contrast, antiepileptics, antidepressants, and antihypertensives are considered first-line options for preventing the attacks [15]. However, a new approach to migraine treatment has arisen from the use of the anti-CGRP monoclonal antibody erenumab, which demonstrated efficacy, tolerability, and good compliance [16]. Despite the numerous synthetic drugs available for the treatment of migraine, the incidence of severe adverse effects [17] has led to the search for new therapeutic options, including herbal formulations and nutraceuticals that maintain acceptable levels of efficacy but have minor side effects [18]. Tanacetum parthenium (feverfew), which belongs to the Asteraceae family, has been traditionally employed as a phytotherapeutic remedy in the treatment of migraine $[19,20]$. This use is consistent with the intrinsic antioxidant and anti-inflammatory properties of the active components of the phytocomplex, including flavonoids, volatile oils, and parthenolide [21,22]. Recently, the neuromodulatory effects of T. parthenium were described, particularly in the inhibition of 5-HT turnover in a preclinical ex vivo model of CSD [23]. Additionally, parthenolide was reported to modulate DA release in the ventral tegmental area [24]. However, there is still lack of scientific literature regarding anti-inflammatory and neuromodulatory effects induced by T. parthenium in the brain, with no studies conducted on hypothalamic pathways.

The aim of this study was to further explain the anti-inflammatory effects of a water extract of T. parthenium. Specifically, the gene expression of interleukin (IL)-1 $\beta$, the IL10 and brain-derived neurotrophic factor (BDNF), and the release of prostaglandin $\mathrm{E}_{2}$ $\left(\mathrm{PGE}_{2}\right)$ were measured in isolated cortex specimens perfused with a $\mathrm{K}^{+} 60 \mathrm{mM}$ KrebsRinger buffer employed as a supraphysiological depolarizing and excitotoxic stimulus. This ex vivo model was selected to reproduce CSD [23]. Additionally, the modulatory effects of T. parthenium on DA release and the gene expression of the DA transporter (DAT) were investigated in hypothalamic HypoE22 cells. A qualitative mass spectrometry (MS) analysis was also conducted to explore the phytochemical composition of the extract. The identified phytocompounds were then analyzed using STITCH (http:/ /stitch.embl.de), a bioinformatic software platform for plotting a targets-components analysis to predict, albeit partially, the mechanism of the action underlying the observed biopharmacological effects.

\section{Results and Discussion}

Initially, the extract was studied phytochemically through the MS technique. The MS qualitative investigation focused on the presence of parthenolide, the characterizing phytochemical of T. parthenium, and gallic acid and resveratrol, which were previously measured in the extract with independent HPLC-fluorimetric analysis [23]. In accordance with our recent studies $[25,26]$, the MS analysis of gallic acid, resveratrol, and parthenolide was conducted in negative ion mode $(\mathrm{m} / \mathrm{z}$ scan mode: $119-556)$, and the $m / z$ ratios of 169.1, 227.2, and 247.3 were monitored to identify gallic acid, resveratrol, and parthenolide, respectively (Figure 1A). In our previous study, catechins were also detected in the extract, although at lower concentrations $(0.11-0.23 \% w / w$ dry extract) compared to gallic acid ( $72.47 \% w / w$ dry extract) and resveratrol $(0.79 \% w / w$ dry extract) [23]. The high intensity of the MS signal measured for gallic acid further supported our previous investigation, which showed gallic acid as the most prominent compound in the T. parthenium extract [23]. 


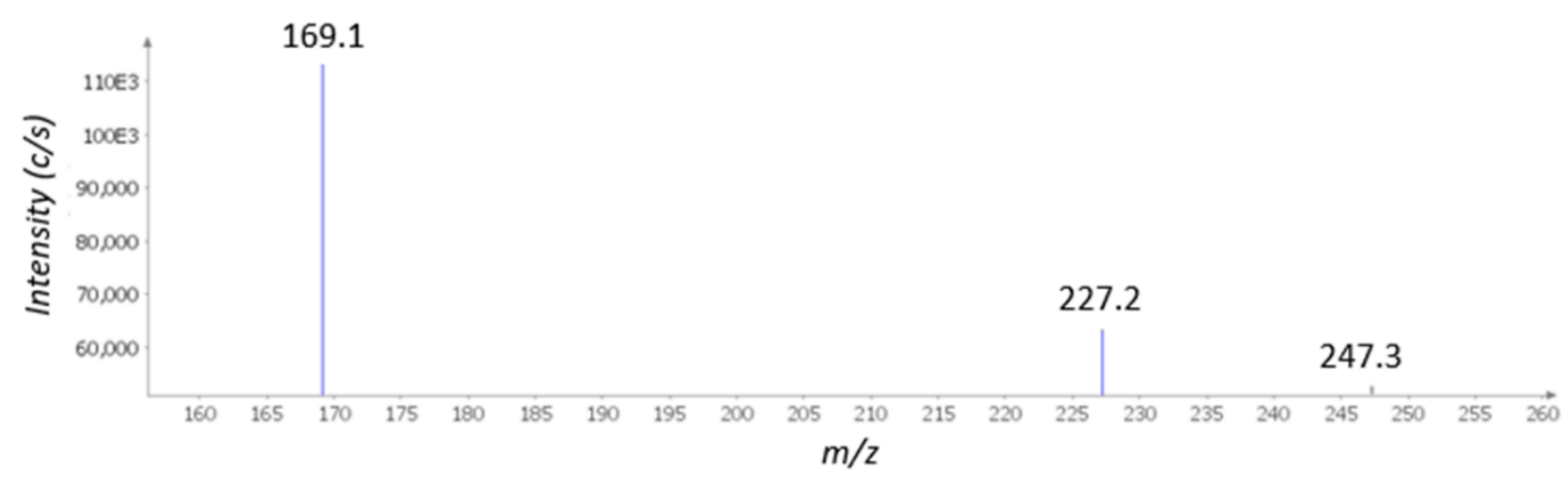

(A)

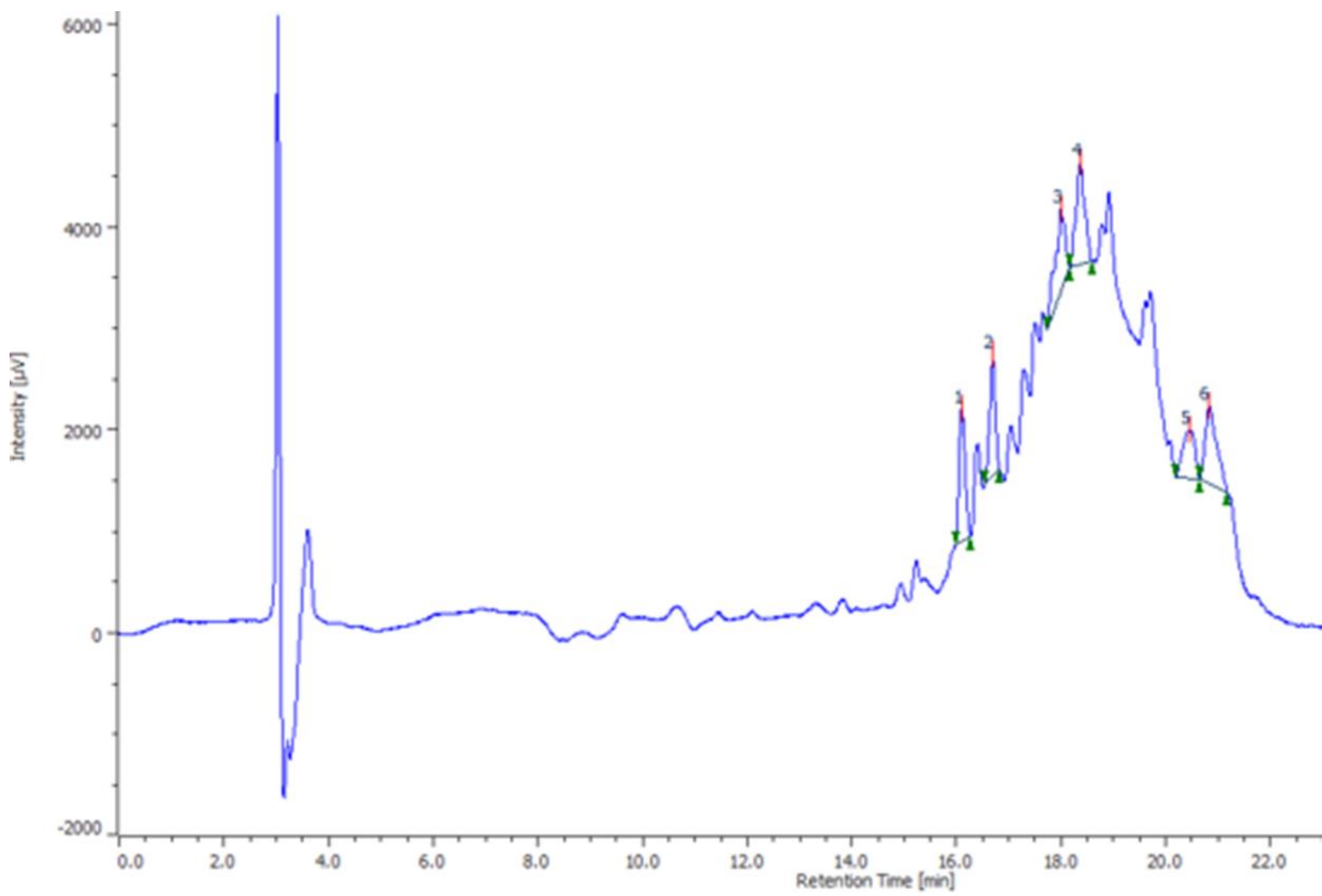

(B)

Figure 1. (A) The qualitative mass spectrometry (MS) analysis conducted on the Tanacetum parthenium water extract. The MS analysis of gallic acid, resveratrol, and parthenolide was conducted in negative ion mode ( $m / z$ scan mode: $119-556)$, and the $\mathrm{m} / \mathrm{z}$ ratios of 169.1, 227.2, and 247.3 were monitored to identify gallic acid, resveratrol, and parthenolide, respectively. (B) The qualitative the high performance liquid chromatography coupled to diode-array detection (HPLC-DAD) analysis showing the presence of catechin (1), chlorogenic acid (2), and rutin (4) in the T. parthenium extract. The chromatographic analysis also showed the presence of unidentified phenolic compounds $(3,5,6)$.

The extract was also qualitatively analyzed using the high performance liquid chromatography coupled to diode-array detection (HPLC-DAD) technique, which revealed the presence of other phenolic compounds in the extract, including catechin (1), chlorogenic acid (2), and rutin (4) (Figure 1B); while the phenolic compounds 3, 5, and 6 were not 
identified. Previous studies have also highlighted the presence of resveratrol in T. parthenium. Resveratrol is present in many plant families and species, leading to an increased interest in finding the compound in plant extracts [27]. This interest is related to the downregulating effects of resveratrol on oxidative and inflammatory pathways [28]. In a preliminary study, we also demonstrated the efficacy of resveratrol in reducing the ex vivo hydrogen-peroxide-induced lipid peroxidation in cortex synaptosomes [29]. The results of the phytochemical analysis were crucial for conducting the preclinical study to determine the efficacy of the T. parthenium water extract in controlling the clinical symptoms related to migraine, particularly the inflammatory pathways related to CSD and the DA signaling at the hypothalamic level. Using the phytochemical composition of the extract, a targets-components analysis was carried out to predict putative targets underlying the antioxidant and anti-inflammatory effects on the brain. The STITCH platform was used to predict direct interactions of gallic acid, resveratrol, catechin, and parthenolide with different proteins involved in inflammatory response (Figure 2), although cyclooxygenase-2 (COX-2), which was found to be up-regulated in experimental models of CSD [30], seemed to play a prominent role in the targets-components analysis. The release of $\mathrm{PGE}_{2}$, the major product and biomarker of COX-2 activity, was measured in isolated cortexes exposed to $\mathrm{K}^{+}$ $60 \mathrm{mM}$ and treated with the T. parthenium extract $(10-100 \mu \mathrm{g} / \mathrm{mL})$. The concentration range was selected basing on our previous study [23]. The blunting effect induced by the extract on the $\mathrm{K}^{+} 60 \mathrm{mM}$-induced $\mathrm{PGE}_{2}$ level (Figure 3) supports the hypothesis that a potential modulation of the inflammatory component characterizes CSD [31].

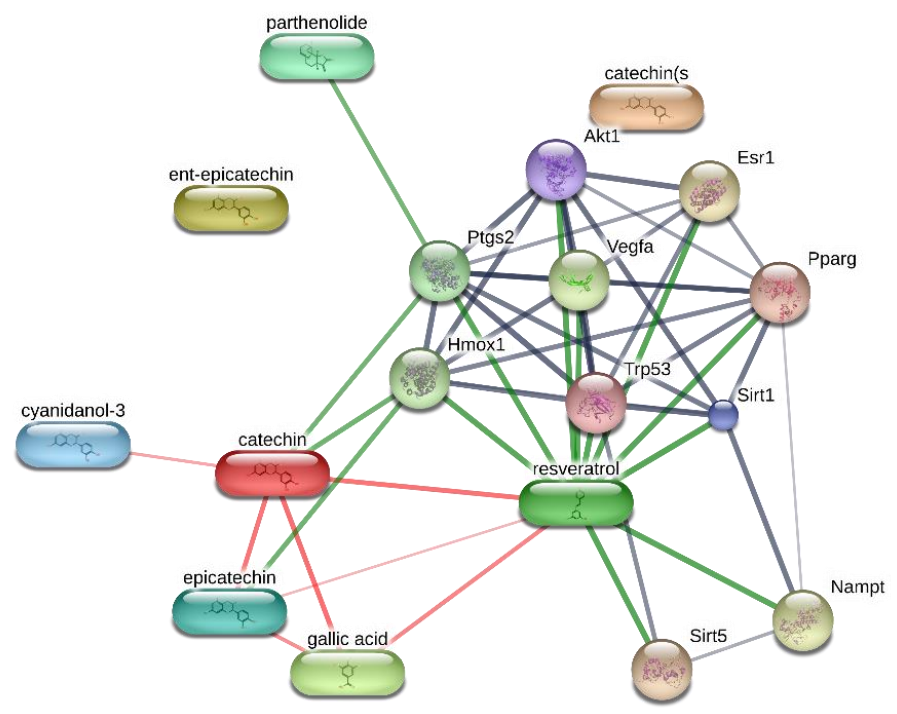

Figure 2. The targets-components analysis conducted via the STITCH platform (http://stitch. embl.de), highlighting the prominent role of cyclooxygenase-2 (COX-2/Ptgs2) in the componentstargets plot.

To confirm this modulation, the gene expressions of pro-inflammatory IL-1 $\beta$ and antiinflammatory IL-10 were evaluated (Figures 4 and 5), and the extract was found to have exerted a significant pro-homeostatic effect on both cytokines. These results also bolster our previous observations of reduced oxidative stress and serotonin turnover induced by the extract in isolated cortexes [23], which could be related, albeit partially, to the intrinsic scavenging and reducing effects of gallic acid, the most abundant compound in the extract [32]. Materazzi et al. showed that parthenolide could also target the ankyrin 1 (TRPA1) channel, and this interaction could partly mediate the T. parthenium anti-migraine effect [22]. The activation of the TRPA1 receptor was also related to anti-inflammatory effects, as evidenced by reduced in vivo COX-2 activity and IL-1 $\beta$ level [33]. In our study, we also investigated the extract's effect on the gene expression of BDNF, and found that the extract exerted a blunting effect on the $\mathrm{K}^{+} 60 \mathrm{mM}$-induced reduction of 
BDNF mRNA levels (Figure 6). Neurotrophins, including BDNF, were related to chronic and episodic migraine, and the plasma levels of this peptide were found to be lower in the migraineurs compared to the control group [34]. The authors of that study also suggested that the reduction of BDNF plasma levels could be related, at least partially, to the hyperactivation of the hypothalamic-pituitary axis that occurs during a migraine attack [35]. It has been proposed that the hypothalamus plays a pivotal role in the onset of a migraine attack [8]. In this context, the attention of researchers has been focused on the involvement of hypothalamic orexigenic factors, including orexins and dopamine. The pharmacological blockade of orexin receptors was found to be effective in counteracting CSD in rats [10], while the stimulation of hypothalamic dopamine signaling is reputed to mediate yawning, fatigue, and alterations in nausea and appetite [11,12]. Additionally, hypothalamic neurons containing DA and orexins are connected to trigemino-vascular thalamic neurons that project to the cortex, thus further highlighting the role of the hypothalamus in the onset of a migraine attack [36,37]. Therefore, the effects of the T. parthenium water extract were evaluated on hypothalamic HypoE22 cells. Initially, the biocompatibility of the extract was investigated in the concentration range of $0.5-100 \mu \mathrm{g} / \mathrm{mL}$. A null effect on cell viability was found in basal conditions, while a stimulation of the viability of the cells exposed to $300 \mu \mathrm{M}$ hydrogen peroxide (Figures 7 and 8) was registered, which further supports the observed protective effects in the cortex. Additionally, the extracellular level of DA was evaluated in cells exposed to the extract at 10-100 $\mu \mathrm{g} / \mathrm{mL}$, and found a concentrationdependent reduction of neurotransmitter release from the hypothalamic cells (Figure 9). We hypothesize that this effect could be related, at least in part, to the presence of parthenolide in the extract. This phytocompound was found to be effective in reducing the spontaneous DA firing in the ventral tegmental area in rats [24]. The same authors also proposed that the inhibition of DA release induced by parthenolide could occur through binding at the membrane monoamine transporters. To explore the mechanism at the basis of the reduced DA level in HypoE22 cells treated with the extract, the gene expression of dopamine transporter (DAT) was measured. The DAT gene expression was significantly up-regulated at the lowest tested concentrations of $10-50 \mu \mathrm{g} / \mathrm{mL}$ (Figure 10), thus indicating a direct modulatory effect of DAT underlying the reduced release of DA from hypothalamic cells. This result is also supported by the docking run, which showed putative interactions of parthenolide with the DAT binding site at sub-micromolar concentration $(\mathrm{Ki}=0.6 \mu \mathrm{M})$ (Figure 11).

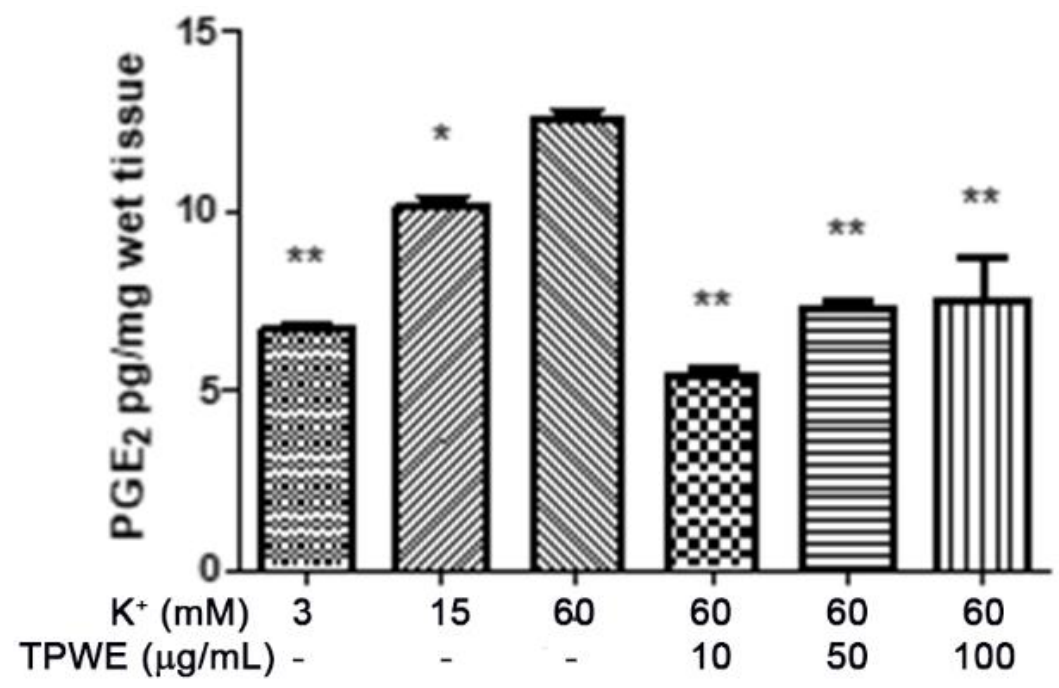

Figure 3. The inhibitory effect induced by Tanacetum parthenium water extract (TPWE: $10-100 \mu \mathrm{g} / \mathrm{mL}$ ) on prostaglandin $\mathrm{E}_{2}\left(\mathrm{PGE}_{2}\right)$ level (pg/mg wet tissue) in isolated cortexes challenged with $\mathrm{K}^{+} 60 \mathrm{mM}$. ANOVA, $p<0.01 ;{ }^{*} p<0.05,{ }^{* *} p<0.01$ vs. the $\mathrm{K}^{+} 60 \mathrm{mM}$ group. 


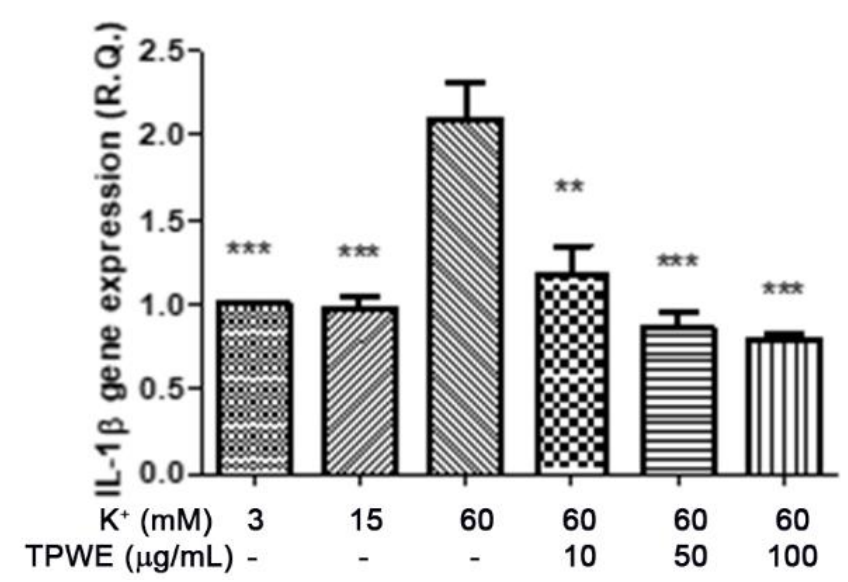

Figure 4. The inhibitory effect induced by the Tanacetum parthenium water extract (TPWE: $10-100 \mu \mathrm{g} / \mathrm{mL}$ ) on interleukin-1 $\beta$ (IL-1 $\beta$ ) gene expression (R.Q. = relative quantification) in isolated cortexes challenged with $\mathrm{K}^{+} 60 \mathrm{mM}$. ANOVA, $p<0.0001$; ${ }^{* *} p<0.01$, ***$p<0.001$ vs. the $\mathrm{K}^{+}$ $60 \mathrm{mM}$ group.

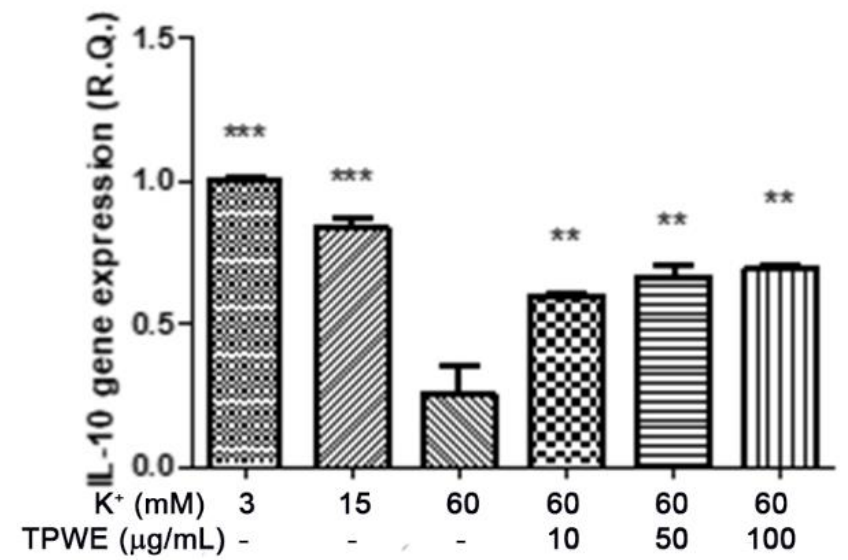

Figure 5. The stimulating effect induced by Tanacetum parthenium water extract (TPWE: $10-100 \mu \mathrm{g} / \mathrm{mL}$ ) on interleukin-10 (IL-10) gene expression (R.Q. = relative quantification) in isolated cortexes challenged with $\mathrm{K}^{+} 60 \mathrm{mM}$. ANOVA, $p<0.0001$; ${ }^{* *} p<0.01$, ${ }^{* * *} p<0.001$ vs. the $\mathrm{K}^{+}$ $60 \mathrm{mM}$ group.

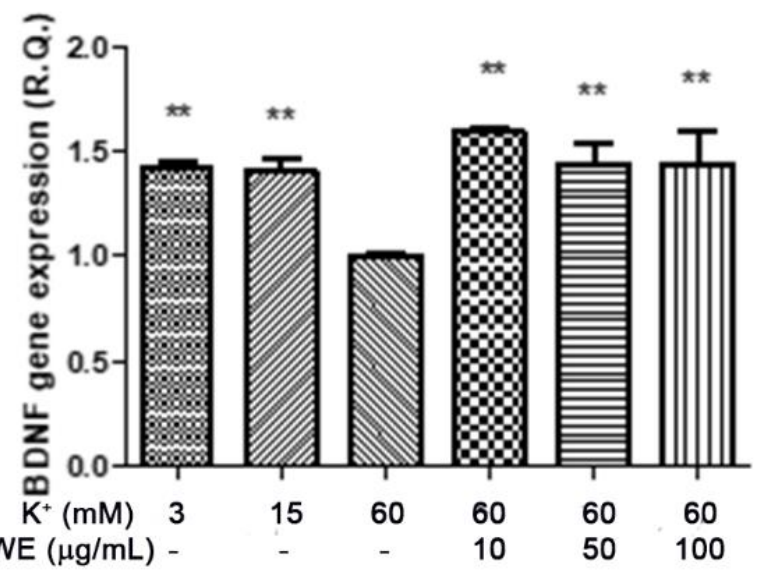

Figure 6. The stimulating effect induced by Tanacetum parthenium water extract (TPWE: $10-100 \mu \mathrm{g} / \mathrm{mL}$ ) on the brain-derived neurotrophic factor (BDNF) gene expression (R.Q. = relative quantification) in isolated cortexes challenged with $\mathrm{K}^{+} 60 \mathrm{mM}$. ANOVA, $p<0.0001$; ${ }^{* *} p<0.01$ vs. the $\mathrm{K}^{+} 60 \mathrm{mM}$ group. 


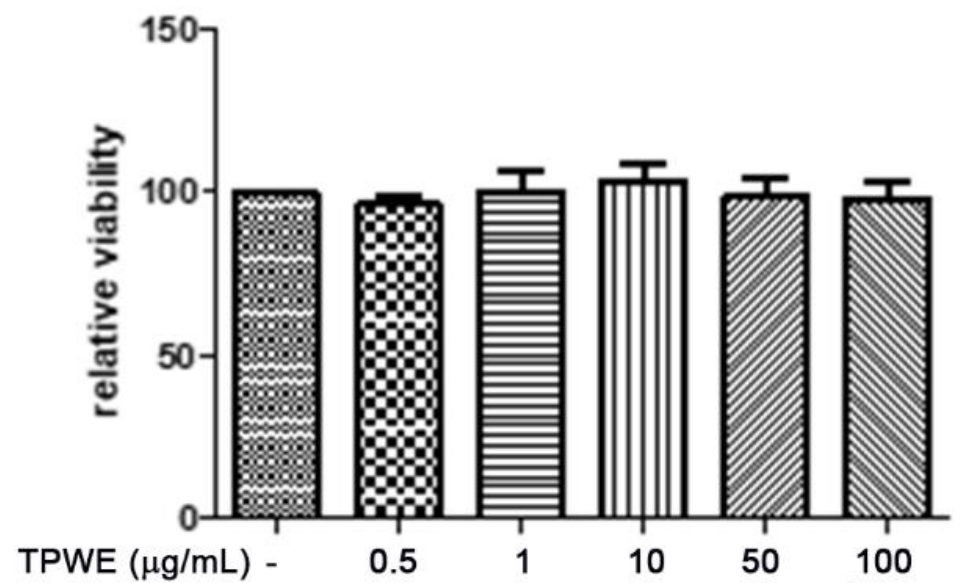

Figure 7. The null effect induced by Tanacetum parthenium (TPWE: $0.5-100 \mu \mathrm{g} / \mathrm{mL}$ ) on the viability of the hypothalamic HypoE22 cell line evaluated using an MTT test.

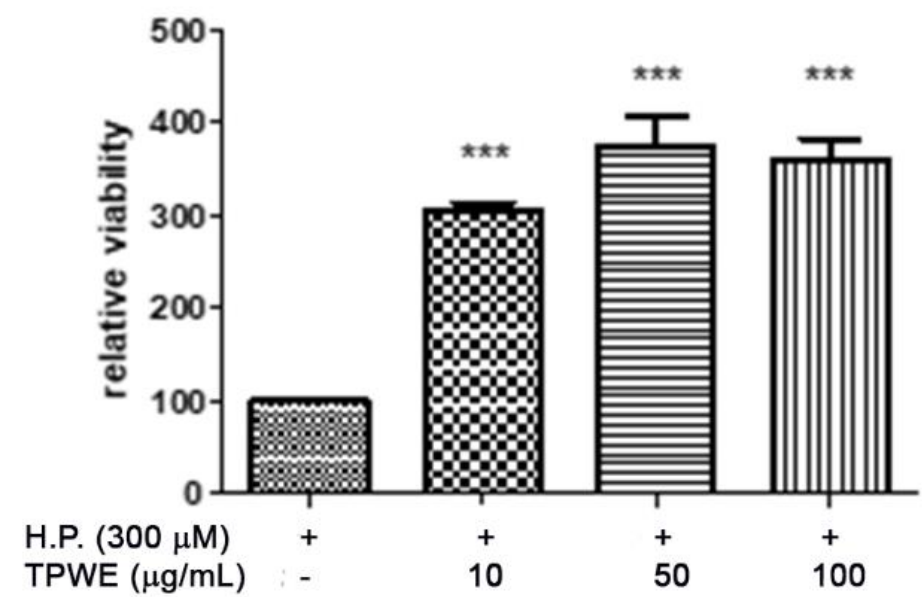

Figure 8. The stimulating effect induced by the Tanacetum parthenium water extract (TPWE: $10-100 \mu \mathrm{g} / \mathrm{mL}$ ) on the viability of HypoE22 cells exposed to $300 \mu \mathrm{M}$ of hydrogen peroxide (H.P.). The cell viability was evaluated using an MTT test. ANOVA, $p<0.0001$, $^{* * *} p<0.001$ vs. the H.P. group.

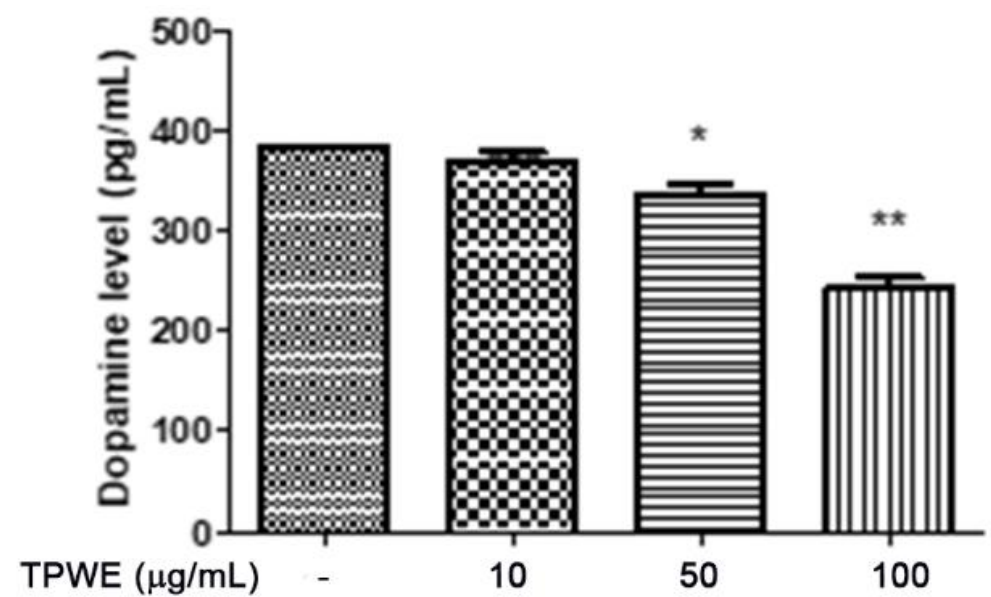

Figure 9. The inhibitory effect induced by Tanacetum parthenium (TPWE: 10-100 $\mu \mathrm{g} / \mathrm{mL}$ ) on dopamine release $\left(\mathrm{pg} / \mathrm{mL}\right.$ ) from hypothalamic HypoE22 cells. ANOVA, $p<0.001 ;{ }^{*} p<0.05,{ }^{* *} p<0.01$ vs. the untreated control (CTR) group. 


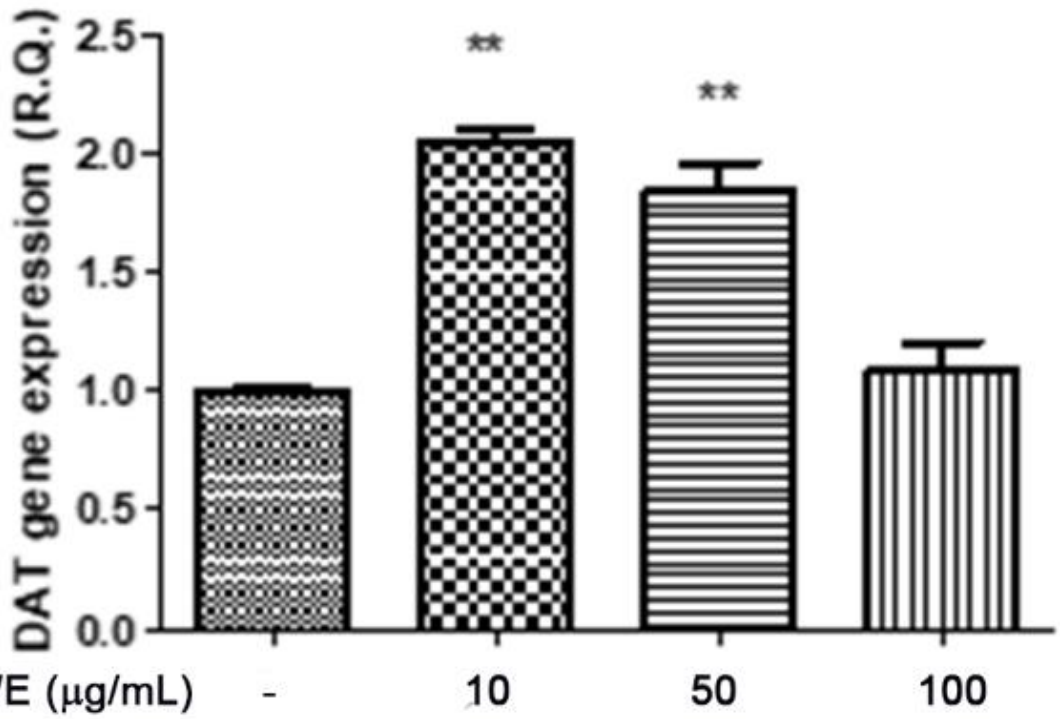

Figure 10. The inhibitory effect induced by Tanacetum parthenium (TPWE: 10-100 $\mu \mathrm{g} / \mathrm{mL}$ ) on dopamine transporter (DAT) gene expression in hypothalamic HypoE22 cells. ANOVA, $p<0.001$; ** $p<0.01$ vs. the untreated control (CTR) group.

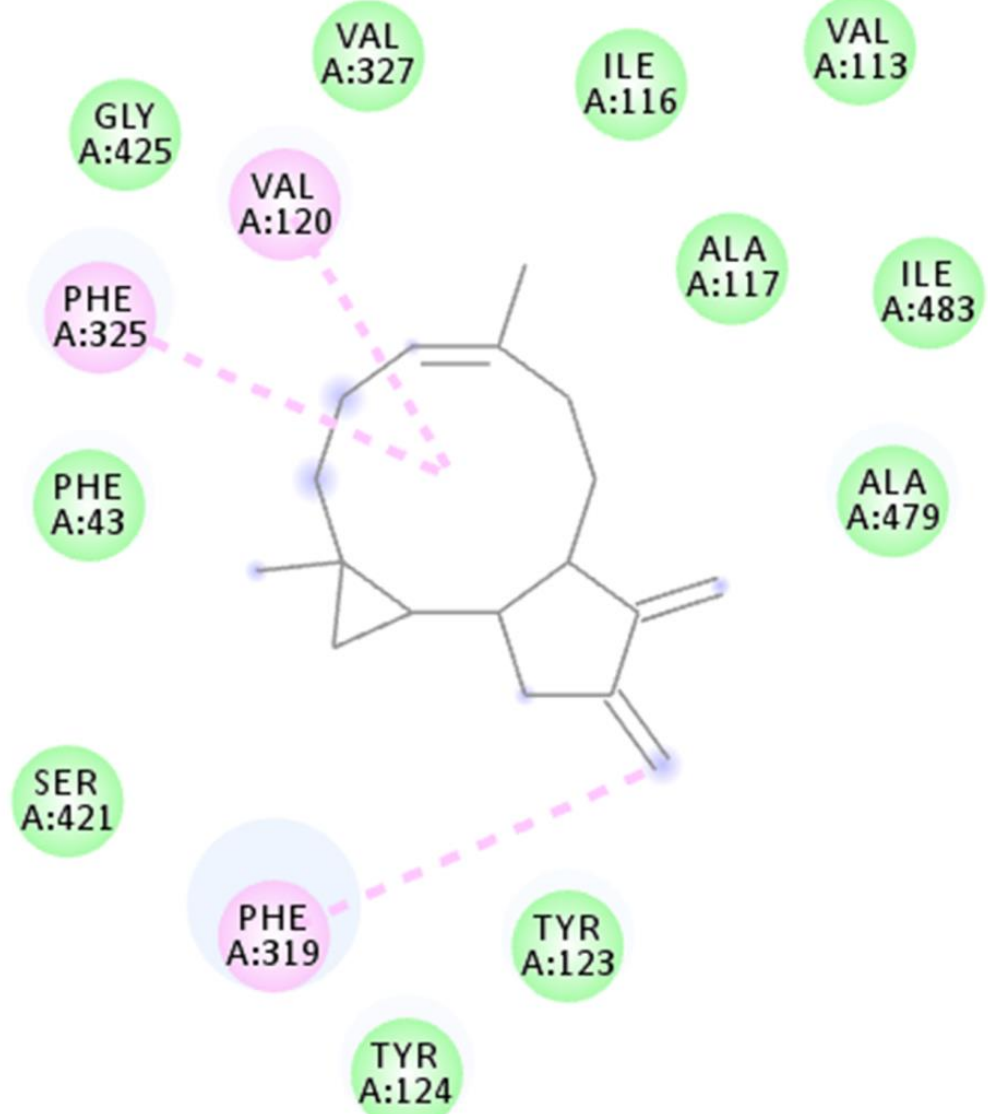

Interactions

van der Waals

Alkyl

Figure 11. Cont. 


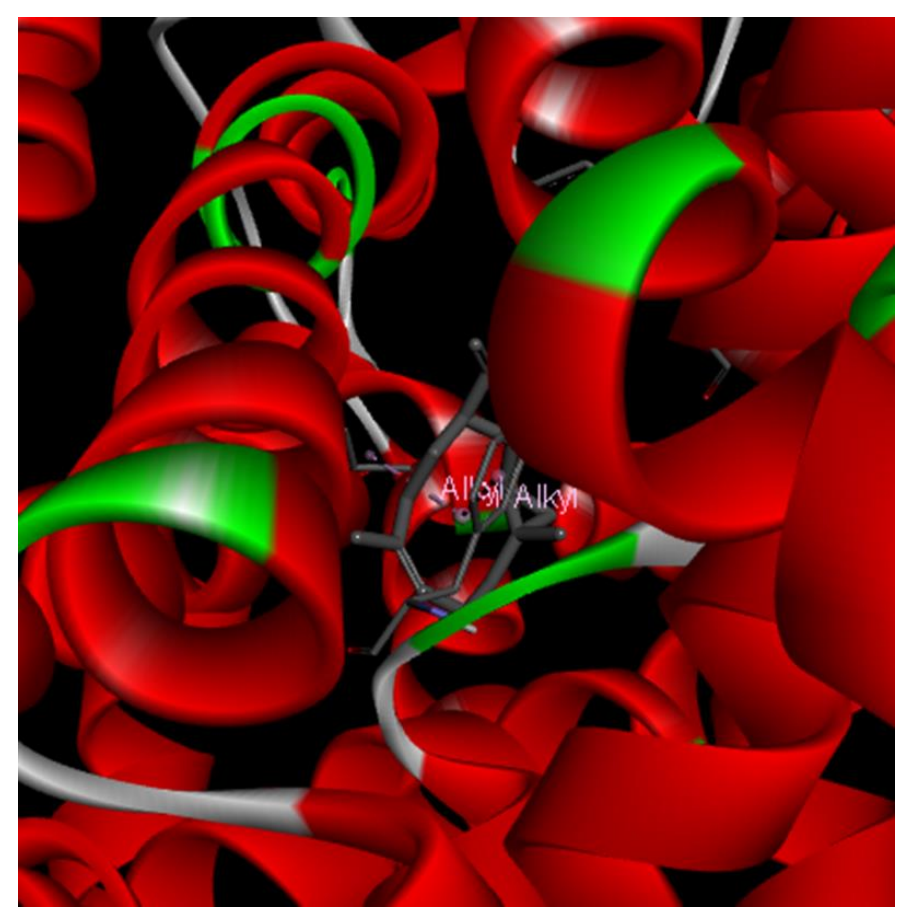

Figure 11. The putative interactions between parthenolide and the dopamine transporter [DAT; Protein Data Bank ID (PDB): 4XNX_1]. The free energy of binding $(\Delta \mathrm{G})$ and affinity (Ki) were $-8.6 \mathrm{kcal} / \mathrm{mol}$ and $0.6 \mu \mathrm{M}$, respectively.

\section{Materials and Methods}

\subsection{Extract Preparation}

The commercial T. parthenium water extract containing $0.5 \%$ parthenolide was provided as dried material by Cristalfarma S.r.l. (Milan, Italy). The extract was rehydrated in a Trans-sonic T460 ultrasonic bath (Elma, Singen, Germany) for $10 \mathrm{~min}$ at room temperature and full power (35 kHz), as previously described [38].

\subsection{Phytochemical Analysis}

The T. parthenium extract was analyzed qualitatively using an expression compact mass spectrometer (CMS) (Advion, Ithaca, NY, USA) in negative ion mode $(\mathrm{m} / \mathrm{z}$ scan mode: 119-556). The signal identification of gallic acid, resveratrol, and parthenolide was realized as previously described $[25,26]$. The qualitative characterization of the extract also included HPLC-DAD analysis. The HPLC apparatus consisted of a PU-2080 PLUS chromatographic pump, a DG-2080-54 line degasser, a mix-2080-32 mixer, a diode array detector (DAD), an AS-2057 PLUS autosampler, and a CO-2060 PLUS column thermostat (all from Jasco, Tokyo, Japan). The integration was performed using ChromNAV2 Chromatography software. The gradient elution (water-acetonitrile: 93:7 ratio) was conducted according to previous literature [39]. The separation was performed on an Infinity lab Poroshell 120 reverse phase column $(\mathrm{C} 18,150 \mathrm{~mm} \times 4.6 \mathrm{~mm}$ i.d., $2.7 \mu \mathrm{m})$ (Agilent Santa Clara, CA, USA). The column temperature was set to $30^{\circ} \mathrm{C}$.

\subsection{In Vitro Studies}

The HypoE22 rat-hypothalamus cell line was purchased from Cedarlane Corporation (Burlington, ON, Canada) and cultured in Dulbecco's Modified Eagle Medium (DMEM) supplemented with $10 \%(v / v)$ heat-inactivated fetal bovine serum and penicillinstreptomycin $(100 \mu \mathrm{g} / \mathrm{mL})$ (all from EuroClone SpA Life-Sciences-Division, Milano, Italy). The cells were grown at $37^{\circ} \mathrm{C}$ in a humidified atmosphere of $5 \% \mathrm{CO}_{2}$. When indicated, the cells were treated with $\mathrm{H}_{2} \mathrm{O}_{2}(300 \mu \mathrm{M})$ for $3 \mathrm{~h}$ and with different concentrations of T. parthenium extract (10-100 $\mu \mathrm{g} / \mathrm{mL})$. The cell viability was evaluated after $24 \mathrm{~h}$ of cul- 
turing using the MTT (3-[4,5-dimethyl-thiazol-2-yl-]-2,5-diphenyl tetrazolium bromide) growth assay (Sigma-Aldrich, St. Louis, MO, USA), based on the capability of viable cells to reduce MTT to a colored formazan product. Details about the protocol were reported in our recent study [40].

\subsection{Ex Vivo CSD Paradigm}

The study included 24 adult male C57BL6 mice housed in Plexiglass cages $(40 \mathrm{~cm}$ $\times 25 \mathrm{~cm} \times 15 \mathrm{~cm})$, with two mice per cage, in climatized colony rooms $\left(22 \pm 1{ }^{\circ} \mathrm{C} ; 60 \%\right.$ humidity), on a $12 \mathrm{~h} / 12 \mathrm{~h}$ light/dark cycle (light phase: 07:00-19:00 h), with free access to tap water and food $24 \mathrm{~h} /$ day throughout the study, with no fasting periods. The mice were fed a standard laboratory diet (3.5\% fat, $63 \%$ carbohydrate, $14 \%$ protein, and $19.5 \%$ other components without a caloric value; $3.20 \mathrm{kcal} / \mathrm{g}$ ). The housing conditions and experimentation procedures were strictly in accordance with the European Union's ethical regulations on the care of animals for scientific research. The experiments were approved by the Local Ethical Committee (University "G. d'Annunzio" of Chieti-Pescara) and the Italian Health Ministry (authorization number: F4738.N.5QP). The mice were euthanized via $\mathrm{CO}_{2}$ inhalation $\left(100 \% \mathrm{CO}_{2}\right.$ at a flow rate of $20 \%$ of the chamber volume per $\left.\mathrm{min}\right)$, and the cortex specimens were immediately collected and maintained in a thermostatic shaking bath at $37^{\circ} \mathrm{C}$ for an incubation period of $1 \mathrm{~h}$ in a Krebs-Ringer buffer at different $\mathrm{K}^{+}$concentrations, as described below:

1. $\mathrm{K}^{+} 3 \mathrm{mM}$, corresponding to the basal condition;

2. $\mathrm{K}^{+} 15 \mathrm{mM}$, corresponding to the physiologic depolarizing stimulus;

3. $\mathrm{K}^{+} 60 \mathrm{mM}$, corresponding to the excitotoxic depolarizing stimulus.

The experiment, which reproduced the neural pathophysiological condition known as CSD, was designed according to previous ex vivo and in vivo studies that described the use of elevated $\mathrm{K}^{+}$concentrations (up to 50-60 mM) to induce injury to the central nervous system [41]. During incubation, the cortex specimens were exposed to T. parthenium $\left(1-100 \mu \mathrm{g} / \mathrm{mL}\right.$ ). Finally, the tissue perfusates were collected, and the $\mathrm{PGE}_{2}$ levels (ng/mg wet tissue) were measured using a radioimmunoassay (RIA), as previously reported [42] Specific anti-8-iso- $\mathrm{PGF}_{2 \alpha}$ and anti-PGE 2 were developed in a rabbit; the cross-reactivity against other prostanoids was $<0.3 \%$. A sample of $100 \mu \mathrm{L}$ of prostaglandin was incubated overnight at $4{ }^{\circ} \mathrm{C}$ with the ${ }^{3} \mathrm{H}$-prostaglandin $(3000 \mathrm{cpm} /$ tube) and an antibody (final dilution: 1:120,000; provided by Professor G. Ciabattoni), in a volume of $1.5 \mathrm{~mL}$ of $0.025 \mathrm{M}$ phosphate buffer. The free and antibody-bound prostaglandins were separated by the addition of $100 \mu \mathrm{L}$ of $5 \%$ bovine serum albumin and $100 \mu \mathrm{L}$ of $3 \%$ charcoal suspension, centrifuged for $10 \mathrm{~min}$ at $4000 \times \mathrm{g}$ at $5{ }^{\circ} \mathrm{C}$, and decanted off the supernatants into a scintillation fluid (Ultima Gold ${ }^{\mathrm{TM}}$, Perkin Elmer, Waltham, MA, USA) for $\beta$-emission counting. The detection limit of the assay method was $0.6 \mathrm{pg} / \mathrm{mL}$.

\subsection{RNA Extraction, Reverse Transcription, and Real-Time Reverse Transcription Polymerase Chain Reaction (Real-Time RT PCR)}

The total RNA was extracted from the mouse cortex specimens and rat hypothalamic HypoE22 cells using TRI Reagent (Sigma-Aldrich, St. Louis, MO, USA), according to the manufacturer's protocol. Contaminating DNA was removed using 2 units of RNase-free DNase 1 (DNA-free kit, Ambion, Austin, TX, USA). The RNA concentration was quantified at $260 \mathrm{~nm}$ using a spectrophotometer reading (BioPhotometer, Eppendorf, Hamburg, Germany), and its purity was assessed using the ratio read at 260 and $280 \mathrm{~nm}$. The quality of the extracted RNA samples was also determined using electrophoresis through agarose gels and staining with ethidium bromide under UV light. One microgram of total RNA extracted from each sample in a $20 \mu \mathrm{L}$ reaction volume was reverse transcribed using a High-Capacity cDNA Reverse Transcription Kit (Thermo Fisher Scientific Inc., Monza, Italy). The reactions were incubated in a 2720 Thermal Cycler (Thermo Fisher Scientific Inc., Monza, Italy) initially at $25^{\circ} \mathrm{C}$ for $10 \mathrm{~min}$, then at $37^{\circ} \mathrm{C}$ for $120 \mathrm{~min}$, and finally at $85^{\circ} \mathrm{C}$ for $5 \mathrm{~s}$. The gene expressions of IL- $1 \beta, \mathrm{IL}-10$, and BDNF in mouse cortex specimens, and DAT in 
HypoE22 cells, were determined via quantitative real-time PCR using TaqMan probe-based chemistry, as previously described [43]. The PCR primers and TaqMan probes, including $\beta$-actin used as the housekeeping gene, were purchased from Thermo Fisher Scientific Inc. The Assays-on-Demand Gene Expression Products used for gene-expression evaluations in the mouse cortex specimens were: Mm00434228_m1 for the IL-1 $\beta$ gene, Mm01288386_m1 for the IL-10 gene, Mm04230607_s1 for the BDNF gene, and Mm00607939_s1 for the $\beta$ actin gene. The Assays-on-Demand Gene Expression Products used for gene-expression evaluations in the rat-hypothalamic HypoE22 cells were: Rn00562224_m1 for the DAT gene, and Rn00667869_m1 for the ACTB gene. The real-time PCR was carried out in triplicate for each cDNA sample for each of the investigated genes. The data were elaborated with the Sequence Detection System (SDS), software version 2.3 (Thermo Fisher Scientific Inc.). The gene expression was relatively quantified using the comparative $2^{-\Delta \Delta \mathrm{Ct}}$ method [44].

\subsection{High-Performance Liquid Chromatography (HPLC) Determination of DA}

The extracellular DA levels were analyzed using an HPLC apparatus consisting of a PU-2080 chromatographic pump (Jasco, Tokyo, Japan) and an ESA Coulochem III coulometric detector (Chelmsford, MA, USA) equipped with a microdialysis cell (ESA$5014 \mathrm{~b}$ ) with a porous graphite working electrode and a solid-state palladium reference electrode. The analytical conditions for biogenic amine identification and quantification were selected in accordance with our previous study [45].

\subsection{Bioinformatics}

The chemical structures were prepared and converted to mol files using ChemSketch software. A compound-target analysis was also conducted using the bioinformatics platform STITCH to predict putative targets. The routine steps in the calculations for the docking analysis involved the preparation of the inhibitors and the protein. The crystal structures of the protein were downloaded from the Protein Data Bank (PDB; https://www.rcsb.org). The PDB code was 4XNX_1 (dopamine transporter: DAT). To prepare the protein for docking calculations, all water molecules and co-crystalized compounds were removed, and polar hydrogen atoms and neutralization were added using the Autodock4 program (Molinspiration database). The starting structures of the secondary metabolites were optimized to their ground-state structures using the Austin Model 1 (AM1) semi-empirical method, and the 3D structures were saved in the mol2 file format. The protein was immersed in a 3D grid box with dimensions of $60 \times 60 \times 60$ and a distance between points of $0.375 \AA$. The Lamarckian genetic algorithm was used to calculate the docking free energy of 250 conformations for each inhibitor. The docking results were clustered and organized according to the docking free energy. The binding site was localized, and the nonbonding interactions were elucidated using the Discovery Studio 5.0 visualizer.

\subsection{Statistical Analysis}

The GraphPad Prism for Windows v5.01 (GraphPad Software, San Diego, CA, USA) was used to analyze the experimental results. The means \pm SD were determined for each experimental group and analyzed using one-way analysis of variance (ANOVA), followed by a Newman-Keuls comparison multiple test. The statistical significance was set at $p<0.05$. The number of animals to be employed in the study was calculated using $\mathrm{G}^{*}$ Power software (v3.1.9.4). The values of the study potency $(1-\beta)$ and the significance level $(\alpha)$ were 0.8 and 0.05 , respectively.

\section{Conclusions}

The findings of our study highlight the efficacy of T. parthenium water extract in controlling the inflammatory pathways that occur during CSD. Additionally, the inhibition of hypothalamic DA release observed in our study further supports the dopaminergic pathways as key targets for novel pharmacological approaches in counteracting migraine attacks. Further studies are needed to confirm the present findings with in vivo models. 
Author Contributions: Conceptualization, G.O., L.B.; methodology, C.F., V.d.G.; software, L.M.; validation, C.F., L.M.; formal analysis, L.R., C.F., G.Z.; investigation, A.C., L.R., S.L., A.A., M.D.A., G.A., S.C.D.S.; resources, G.O.; data curation, L.R., C.F., G.O.; writing-original draft preparation, C.F.; writing-review and editing, A.C., L.R., C.F., G.O.; visualization, L.B., G.Z.; supervision, L.B.; project administration, L.M., G.O., C.F.; funding acquisition, L.M., G.O., C.F. All authors have read and agreed to the published version of the manuscript.

Funding: This work was supported by a grant from Cristalfarma S.r.l. (Milan, Italy), within a project to study the applicative potential of herbal-derived phytocomplexes (Coordinators: Luigi Menghini, Giustino Orlando, and Claudio Ferrante).

Institutional Review Board Statement: The experiments were approved by the Local Ethical Committee (University "G. d'Annunzio" of Chieti-Pescara) and the Italian Health Ministry (authorization number: F4738.N.5QP).

Informed Consent Statement: Not applicable.

Data Availability Statement: The data presented in this study are available on request from the corresponding author.

Acknowledgments: The authors would like to thank Lucio Boschi (Veridia Italia S.r.l.) for technical assistance during the study.

Conflicts of Interest: The authors declare no conflict of interest.

Sample Availability: Samples of the compounds are available from the authors.

\section{References}

1. Rajapakse, T.; Davenport, W.J. Phytomedicines in the Treatment of Migraine. CNS Drugs 2019, 33, 399-415. [CrossRef] [PubMed]

2. Hering, R.; Glover, V.; Pattichis, K.; Catarci, T.; Steiner, T.J. 5HT in migraine patients with medication-induced headache. Cephalalgia 1993, 13, 410-412. [CrossRef] [PubMed]

3. Lance, J.W. 5-Hydroxytryptamine and its role in migraine. Eur. Neurol. 1991, 31, 279-281. [CrossRef] [PubMed]

4. Massiou, H.; Bousser, M.G. Prophylactic drug treatment of migraine. Rev. Neurol. (Paris) 2005, 161, 681-684. [CrossRef]

5. Noseda, R.; Burstein, R. Migraine pathophysiology: Anatomy of the trigeminovascular pathway and associated neurological symptoms, cortical spreading depression, sensitization, and modulation of pain. Pain 2013, 154 (Suppl. 1), S44-S53. [CrossRef] [PubMed]

6. Edvinsson, L.; Haanes, K.A.; Warfvinge, K.; Krause, D.N. CGRP as the target of new migraine therapies-successful translation from bench to clinic. Nat. Rev. Neurol. 2018, 14, 338-350. [CrossRef]

7. Supornsilpchai, W.; Sanguanrangsirikul, S.; Maneesri, S.; Srikiatkhachorn, A. Serotonin depletion, cortical spreading depression, and trigeminal nociception. Headache 2006, 46, 34-39. [CrossRef]

8. May, A.; Burstein, R. Hypothalamic regulation of headache and migraine. Cephalalgia 2019, 39, 1710-1719. [CrossRef]

9. Kalra, S.P.; Dube, M.G.; Pu, S.; Xu, B.; Horvath, T.L.; Kalra, P.S. Interacting appetite-regulating pathways in the hypothalamic regulation of body weight. Endocr. Rev. 1999, 20, 68-100. [CrossRef]

10. Hoffmann, J.; Supronsinchai, W.; Akerman, S.; Andreou, A.P.; Winrow, C.J.; Renger, J.; Hargreaves, R.; Goadsby, P.J. Evidence for orexinergic mechanisms in migraine. Neurobiol. Dis. 2015, 74, 137-143. [CrossRef] [PubMed]

11. Akerman, S.; Goadsby, P.J. Dopamine and migraine: Biology and clinical implications. Cephalalgia 2007, 27, 1308-1314. [CrossRef] [PubMed]

12. Charbit, A.R.; Akerman, S.; Goadsby, P.J. Dopamine: What's new in migraine? Curr. Opin. Neurol. 2010, 23, 275-281. [CrossRef]

13. Eken, C. Critical reappraisal of intravenous metoclopramide in migraine attack: A systematic review and meta-analysis. Am. J. Emerg. Med. 2015, 33, 331-337. [CrossRef] [PubMed]

14. Lupi, C.; Benemei, S.; Guerzoni, S.; Pellesi, L.; Negro, A. Pharmacokinetics and pharmacodynamics of new acute treatments for migraine. Expert Opin. Drug Metab. Toxicol. 2019, 15, 189-198. [CrossRef]

15. Loder, E.; Rizzoli, P. Pharmacologic Prevention of Migraine: A Narrative Review of the State of the Art in 2018. Headache 2018, 58 (Suppl. 3), 218-229. [CrossRef] [PubMed]

16. Frediani, F.; D'Arrigo, G.; Galli, A.; Altavilla, R.; Di Fiore, P. Exploring new strategy in erenumab therapy for migraine patients. Neurol. Sci. 2020, 41 (Suppl. 2), 507-508. [CrossRef]

17. Wider, B.; Pittler, M.H.; Ernst, E. Feverfew for preventing migraine. Cochrane Database Syst. Rev. 2015, 4, CD002286. [CrossRef]

18. Sangermani, R.; Boncimino, A. The use of nutraceutics in children's and adolescent's headache. Neurol. Sci. 2017, 38 (Suppl. 1), 121-124. [CrossRef]

19. Guilbot, A.; Bangratz, M.; Ait Abdellah, S.; Lucas, C. A combination of coenzyme Q10, feverfew and magnesium for migraine prophylaxis: A prospective observational study. BMC Complement. Altern. Med. 2017, 17, 433. [CrossRef] 
20. Moscano, F.; Guiducci, M.; Maltoni, L.; Striano, P.; Ledda, M.G.; Zoroddu, F.; Raucci, U.; Villa, M.P.; Parisi, P. An observational study of fixed-dose Tanacetum parthenium nutraceutical preparation for prophylaxis of pediatric headache. Ital. J. Pediatr. 2019, 45, 36. [CrossRef]

21. Pareek, A.; Suthar, M.; Rathore, G.S.; Bansal, V. Feverfew (Tanacetum parthenium L.): A systematic review. Pharmacogn. Rev. 2011, 5, 103-110. [CrossRef]

22. Materazzi, S.; Benemei, S.; Fusi, C.; Gualdani, R.; De Siena, G.; Vastani, N.; Andersson, D.A.; Trevisan, G.; Moncelli, M.R.; Wei, X.; et al. Parthenolide inhibits nociception and neurogenic vasodilatation in the trigeminovascular system by targeting the TRPA1 channel. Pain 2013, 154, 2750-2758. [CrossRef]

23. Di Giacomo, V.; Ferrante, C.; Ronci, M.; Cataldi, A.; Di Valerio, V.; Rapino, M.; Recinella, L.; Chiavaroli, A.; Leone, S.; VladimirKnežević, S.; et al. Multiple pharmacological and toxicological investigations on Tanacetum parthenium and Salix alba extracts: Focus on potential application as anti-migraine agents. Food Chem. Toxicol. 2019, 133, 110783. [CrossRef]

24. Schwarz, D.; Bloom, D.; Castro, R.; Pagán, O.R.; Jiménez-Rivera, C.A. Parthenolide Blocks Cocaine's Effect on Spontaneous Firing Activity of Dopaminergic Neurons in the Ventral Tegmental Area. Curr. Neuropharmacol. 2011, 9, 17-20. [CrossRef] [PubMed]

25. Ferrante, C.; Angelini, P.; Venanzoni, R.; Angeles Flores, G.; Tirillini, B.; Recinella, L.; Chiavaroli, A.; Brunetti, L.; Leone, S.; Di Simone, S.C.; et al. Antimicrobial, Antioxidant, and Antiproliferative Effects of Coronilla minima: An Unexplored Botanical Species. Antibiotics 2020, 9, 611. [CrossRef] [PubMed]

26. Ferrante, C.; Chiavaroli, A.; Angelini, P.; Venanzoni, R.; Angeles Flores, G.; Brunetti, L.; Petrucci, M.; Politi, M.; Menghini, L.; Leone, S.; et al. Phenolic Content and Antimicrobial and Anti-Inflammatory Effects of Solidago virga-aurea, Phyllanthus niruri, Epilobium angustifolium, Peumus boldus, and Ononis spinosa Extracts. Antibiotics 2020, 9, 783. [CrossRef] [PubMed]

27. Lim, J.D.; Song, J.Y.; Lee, S.J.; Chung, I.M.; Kim, M.J.; Heo, K.; Yu, C.Y. Comparison of resveratrol contents in medicinal plants. Korean J. Med. Crop Sci. 2004, 12, 163-170.

28. Bertelli, A.A.E. Modulatory effect of resveratrol, a natural phytoalexin, on endothelial adhsion molecules and intracellular signal transduction. Pharm. Biol. 1998, 36, 44-52. [CrossRef]

29. Chiavaroli, A.; Brunetti, L.; Orlando, G.; Recinella, L.; Ferrante, C.; Leone, S.; Di Michele, P.; Di Nisio, C.; Vacca, M. Resveratrol inhibits isoprostane production in young and aged rat brain. J. Biol. Regul. Homeost. Agents 2010, 24, 441. [PubMed]

30. Yokota, C.; Kuge, Y.; Inoue, H.; Tamaki, N.; Minematsu, K. Bilateral induction of the S-100A9 gene in response to spreading depression is modulated by the cyclooxygenase-2 activity. J. Neurol. Sci. 2005, 234, 11-16. [CrossRef] [PubMed]

31. Jander, S.; Schroeter, M.; Peters, O.; Witte, O.W.; Stoll, G. Cortical spreading depression induces proinflammatory cytokine gene expression in the rat brain. J. Cereb. Blood Flow Metab. 2001, 21, 218-225. [CrossRef] [PubMed]

32. Dutta, M.; Paul, G. Gallic acid protects rat liver mitochondria ex vivo from bisphenol a induced oxidative stress mediated damages. Toxicol. Rep. 2019, 6, 578-589. [CrossRef] [PubMed]

33. Alvarenga, E.M.; Souza, L.K.; Araújo, T.S.; Nogueira, K.M.; Sousa, F.B.; Araújo, A.R.; Martins, C.S.; Pacífico, D.M.; de C Brito, G.A.; Souza, E.P.; et al. Carvacrol reduces irinotecan-induced intestinal mucositis through inhibition of inflammation and oxidative damage via TRPA1 receptor activation. Chem. Biol. Interact. 2016, 260, 129-140. [CrossRef] [PubMed]

34. Martins, L.B.; Duarte, H.; Ferreira, A.V.; Rocha, N.P.; Teixeira, A.L.; Domingues, R.B. Migraine is associated with altered levels of neurotrophins. Neurosci. Lett. 2015, 587, 6-10. [CrossRef] [PubMed]

35. Juang, K.D.; Yang, C.Y. Psychiatric comorbidity of chronic daily headache: Focus on traumatic experiences in childhood, post-traumatic stress disorder and suicidality. Curr. Pain Headache Rep. 2014, 18, 405. [CrossRef] [PubMed]

36. Noseda, R.; Jakubowski, M.; Kainz, V.; Borsook, D.; Burstein, R. Cortical projections of functionally identified thalamic trigeminovascular neurons: Implications for migraine headache and its associated symptoms. J. Neurosci. 2011, 31, 14204-14217. [CrossRef]

37. Noseda, R.; Kainz, V.; Borsook, D.; Burstein, R. Neurochemical pathways that converge on thalamic trigeminovascular neurons: Potential substrate for modulation of migraine by sleep, food intake, stress and anxiety. PLoS ONE 2014, 9, e103929. [CrossRef]

38. Menghini, L.; Leporini, L.; Vecchiotti, G.; Locatelli, M.; Carradori, S.; Ferrante, C.; Zengin, G.; Recinella, L.; Chiavaroli, A.; Leone, S.; et al. Crocus sativus L. stigmas and byproducts: Qualitative fingerprint, antioxidant potentials and enzyme inhibitory activities. Food Res. Int. 2018, 109, 91-98. [CrossRef]

39. Ferrante, C.; Recinella, L.; Ronci, M.; Menghini, L.; Brunetti, L.; Chiavaroli, A.; Leone, S.; Di Iorio, L.; Carradori, S.; Tirillini, B.; et al. Multiple pharmacognostic characterization on hemp commercial cultivars: Focus on inflorescence water extract activity. Food Chem. Toxicol. 2019, 125, 452-461. [CrossRef]

40. Di Giacomo, V.; Chiavaroli, A.; Orlando, G.; Cataldi, A.; Rapino, M.; Di Valerio, V.; Leone, S.; Brunetti, L.; Menghini, L.; Recinella, L.; et al. Neuroprotective and Neuromodulatory Effects Induced by Cannabidiol and Cannabigerol in Rat Hypo-E22 cells and Isolated Hypothalamus. Antioxidants 2020, 9, 71. [CrossRef]

41. Raiteri, L.; Stigliani, S.; Zedda, L.; Raiteri, M.; Bonanno, G. Multiple mechanisms of transmitter release evoked by "pathologically" elevated extracellular [K+]: Involvement of transporter reversal and mitochondrial calcium. J. Neurochem. 2002, 80, 706-714. [CrossRef] [PubMed]

42. Locatelli, M.; Ferrante, C.; Carradori, S.; Secci, D.; Leporini, L.; Chiavaroli, A.; Leone, S.; Recinella, L.; Orlando, G.; Martinotti, S.; et al. Optimization of Aqueous Extraction and Biological Activity of Harpagophytum procumbens Root on Ex Vivo Rat Colon Inflammatory Model. Phytother. Res. 2017, 31, 937-944. [CrossRef] [PubMed] 
43. Ferrante, C.; Orlando, G.; Recinella, L.; Leone, S.; Chiavaroli, A.; Di Nisio, C.; Shohreh, R.; Manippa, F.; Ricciuti, A.; Vacca, M.; et al. Central apelin-13 administration modulates hypothalamic control of feeding. J. Biol. Regul. Homeost. Agents 2016, 30, 883-888. [PubMed]

44. Livak, K.J.; Schmittgen, T.D. Analysis of relative gene expression data using real-time quantitative PCR and the 2(-Delta Delta C(T)) Method. Methods 2001, 25, 402-408. [CrossRef] [PubMed]

45. Iodice, P.; Ferrante, C.; Brunetti, L.; Cabib, S.; Protasi, F.; Walton, M.E.; Pezzulo, G. Fatigue modulates dopamine availability and promotes flexible choice reversals during decision making. Sci. Rep. 2017, 7, 535. [CrossRef] [PubMed] 